\section{SEM Short Courses for Industry: the Lehigh Microscopy School as an example}

\author{
Charles E. Lyman \\ Department of Materials Science and Engineering \\ Lehigh University, Bethlehem, PA \\ charles.lyman@lehigh.edu
}

\section{Introduction}

Short courses in scanning electron microscopy (SEM) can quickly sharpen practical skills for industrial microscopists. The SEM and the energy-dispersive X-ray spectrometer (EDS) together constitute one of the most powerful and versatile instruments available for solving industrial problems, but interpreting images and spectra is not quite as simple as acquiring them. Applications of SEM span many disciplines, and each application may require knowledge of different aspects of the microscope, and of the industrial problem at hand, to successfully interpret the images and data obtained. Regardless of the problem, whether transistors or trachea cells, the interpretation of SEM images relies upon the microscopist's understanding the fundamentals of image formation as well as the practical aspects of specimen preparation and microscope operation. Many people using SEMs today have not taken any courses beyond the on-site and demo-lab instruction provided by SEM vendors. Equipment manufacturers provide excellent training on how to use the knobs and menus on the SEM to produce useful images and data via the embedded software functions. Since there are many options and setup procedures, these instrument-specific courses are valuable for the novice and expert alike.

The function of other types of short courses, like those offered at the Lehigh Microscopy School [1], is to extend the SEM operator's knowledge from knob-twisting to the performance and interpretation of morphological, compositional, and crystallographic analyses. Some of the factors that make such courses successful are the lecturers employed, the textbooks used, the integration of lecture and laboratory experiences, the social networking, and the overall course organization.

\section{Lecturers and lab instructors}

When Joe Goldstein planned his initial SEM short course at Lehigh University in 1970, commercial SEMs had only been available for 5 years. His first priority was to find lecturers who knew enough about these new instruments to provide credible information about the operation of the SEM, the interpretation of SEM images, and the use of EDS detectors on SEMs. Fortunately, experts in electron probe microanalysis (EPMA) were also often knowledgeable about the electron optics necessary to produce a 10-nm electron beam that could be scanned to form images from electron signals. In the earliest years of the course, Goldstein hired four young scientists at the beginning of their careers who have since become leaders in various areas of SEM/EDS theory and practice: Eric Lifshin (see Figure 1), Dale Newbury, David Joy, and Patrick Echlin. These experts continue to lecture and lead laboratory exercises at the Lehigh Microscopy School. As the field progressed and the SEM short course grew in size, experts in various sub-areas of SEM were hired until today 18 lecturers

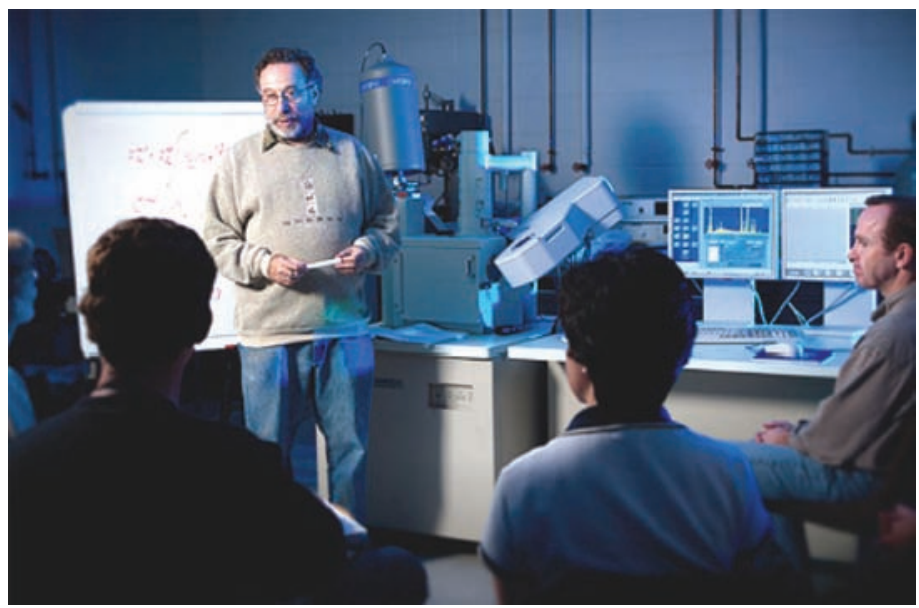

Eric Lifshin teaching in an $x$-ray microanalysis session at the Lehigh Microscopy School.

and lab instructors are employed for the first-week flagship course "Scanning Electron Microscopy and X-ray Microanalysis."

\section{Books and stuff}

Lectures that are easy-to-understand, practical, and interesting are the heart of a successful short course. From its earliest years, a comprehensive set of lecture notes, containing all the slides shown in the lectures, has been distributed to all participants. Students in short courses also want a detailed textbook to read after they return from the course. Thus, in 1975 Joe Goldstein led a team in the writing of one of the early textbooks [2] on this subject. However, SEM and EDS technology has not been static, and new developments every few years inspired another textbook that is now in its third edition [3]. Each participant receives a copy of this textbook. Many of the other lecturers at the Lehigh Microscopy School have written their own books in their respective fields of expertise.

An important task for any course about analytical instruments is to integrate the lectures with laboratory exercises so that the main points can be fully understood. At the Lehigh SEM course, there are 16 separate lab groups so that the number of participants in each group is small enough for everyone in the room to be engaged. For the first three days of the main course, everyone does the same experiments, which are designed to show (a) the operating modes of the SEM, (b) the concepts of imaging with various electron detectors, and (c) the practical aspects of $\mathrm{X}$-ray spectrum analysis and X-ray mapping. The experimental setups and worked solutions to these exercises are fully described

\begin{tabular}{|c|c|c|c|c|c|}
\hline Sunday & Monday & Tuesday & Wednesday & Thursday & Friday \\
\hline $\begin{array}{l}\text { Beginner's } \\
\text { Course }\end{array}$ & $\begin{array}{c}\text { SEM } \\
\text { Imaging } \\
\text { Modes }\end{array}$ & $\begin{array}{l}\text { SEM } \\
\text { Imaging }\end{array}$ & $\begin{array}{c}\text { X-ray } \\
\text { Analysis }\end{array}$ & $\begin{array}{l}\text { VP, Low-volt } \\
\text { Options }\end{array}$ & $\begin{array}{l}\text { Options } \\
\text { Course } \\
\text { Summary }\end{array}$ \\
\hline $\begin{array}{c}\text { Separate } \\
\text { Introductory }\end{array}$ & & n Lectures & and Labs & & $\begin{array}{l}\text { onal } \\
\text { ions }\end{array}$ \\
\hline Course & & $\begin{array}{l}\text { ution Mode } \\
\text { ofrent Mode } \\
\text { of-Field Mode } \\
\text { oltage Mode }\end{array}$ & & & \\
\hline
\end{tabular}

Figure 2. SEM course schedule. On Sunday, an introductory course introduces the basics of imaging and X-ray analysis. During Monday, Tuesday, and Wednesday the core topics of imaging and X-ray microanalysis are presented. On Thursday and Friday, participants may choose from among 30 special topic lectures. 

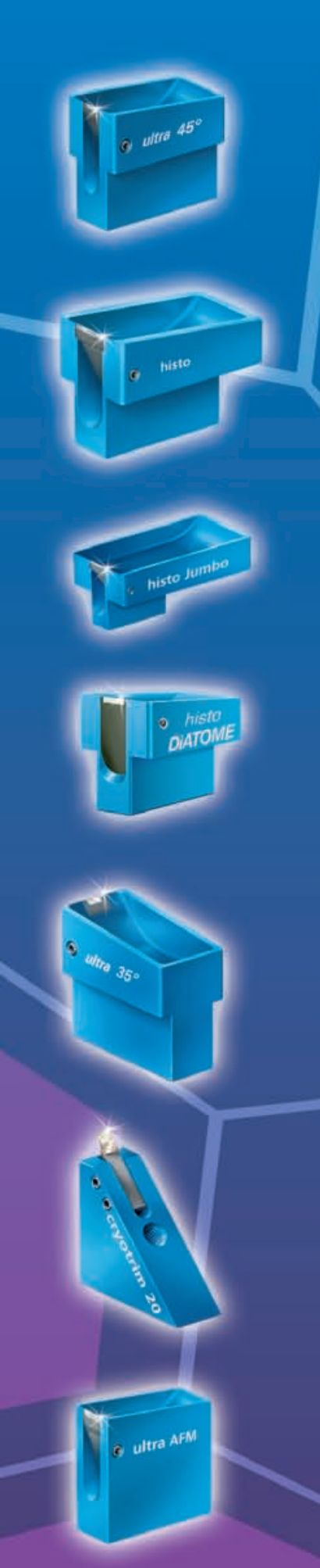

\section{DIATOME}

for all your sectioning requirements

ultra $45^{\circ}$

\section{semi}

cryo at low temperature.

\section{histo}

\section{ultra $35^{\circ}$}

cryo-P

a cryo knife with a patented

platform for section pick up.

cryo immuno

for the Tokuyasu technique.

ultra sonic

cryotrim with diamond blades.

cryo $25^{\circ}$

STATIC LINE II

charging in ultramicrotomy.
DIATOME Diamond Knives Development, Manufacturing, and Customer Service since 1970

\section{What have we achieved in this period?}

the first diamond knife with an absolutely

score-free, hydrophilic cutting edge.

the first diamond knife for alternating
sectioning ultrathin/semithin.

the diamond knife for sectioning

the first diamond knife for semithin sections for light microscopy.

the diamond knife for optimized sectioning

results in almost all applications.

the optimized cryo diamond knife

the oscillating diamond knife for room temperature sectioning.

45 and 25 optimizing trimming

ultra AFM \& cryo AFM the first diamond knives for AFM at room and low temperatures.

for sectioning frozen hydrated specimens.

the ionizer for eliminating electrostatic

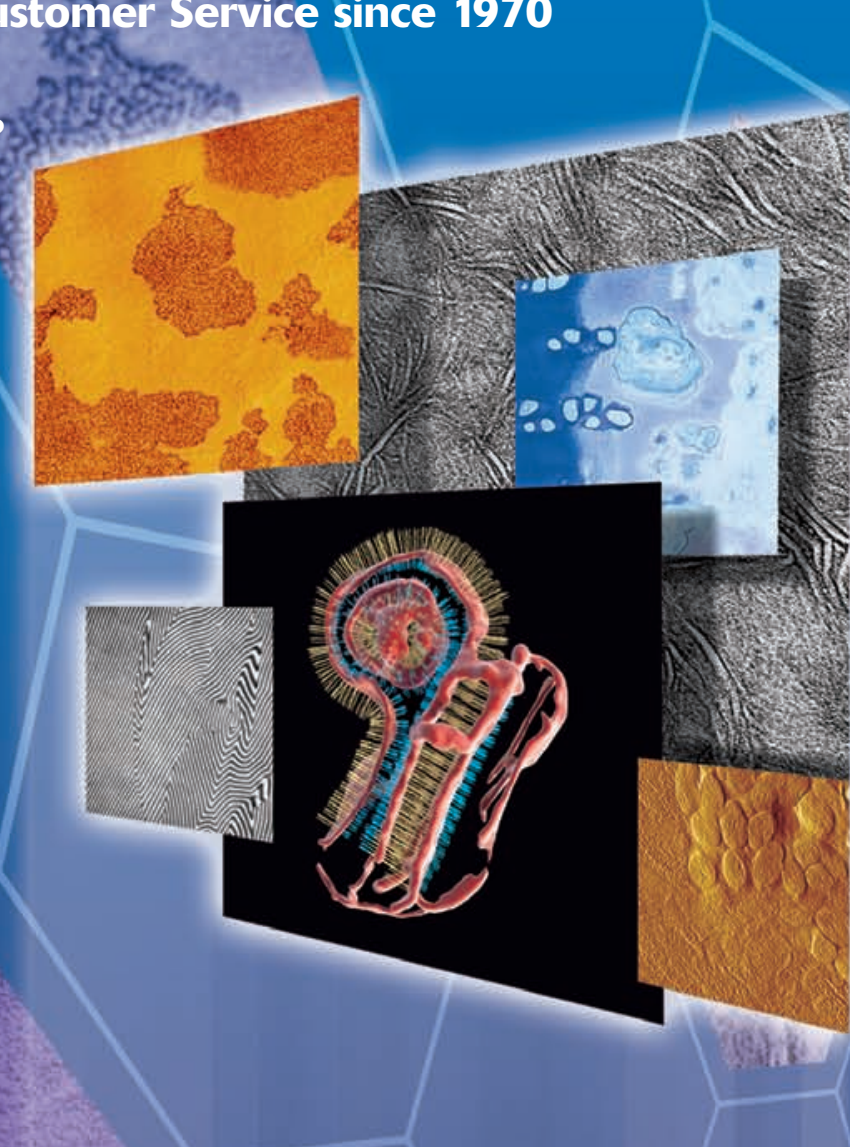

What services can we offer you?

Technical assistance in all fields of ultramicrotomy.

Free sectioning tests for all types of samples.

Make use of our many years of experience in perfecting our knives.

Custom knives, tools, and boats.

Special purchase programs.

Workshops and training?
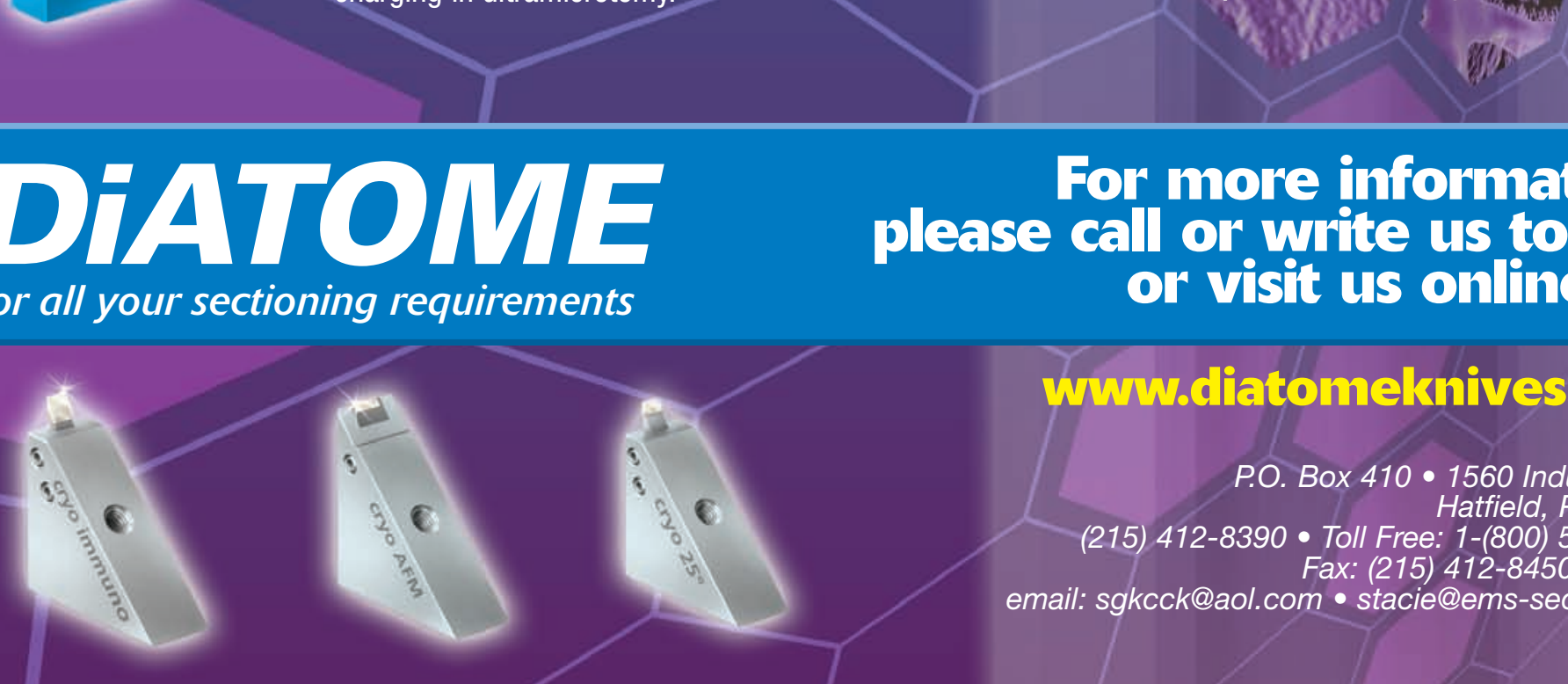

www.diatomeknives.com

P.O. Box $410 \cdot 1560$ Industry Rd. Hatfield, $\mathrm{Pa} 19440$

(215) 412-8390 • Toll Free: 1-(800) 523-5874

Fax: (215) 412-8450 or 8452

email:sgkcck@aol.com•stacie@ems-secure.com 
in a 90-page lab workbook given to each participant. Rounding out the list of items distributed to each attendee is a CD-ROM with images, data, and computer programs. Certain files on the CD, e.g., programs for Monte Carlo simulation of electron beam-specimen interactions and X-ray spectrum simulation, are demonstrated in special computer lab sessions later in the week.

\section{The schedule}

One feature of the Lehigh SEM course may seem rather surprising. In the same lectures there are people who are new to the SEM ("my boss told me last month to take over the SEM") who sit alongside people with 30 years' experience. The Lehigh SEM course accommodates people with differing levels of experience by teaching the same topics at three levels of complexity. This can be seen in the course schedule shown in Figure 2. On the Sunday before the main course begins, a separate one-day course introduces SEM and EDS concepts from the very beginning. On Monday, Tuesday, and Wednesday these same concepts are discussed a second time in the main course lectures and a third time in the laboratories, where more extensive small group discussions can take place. Indeed, small-group lab sessions are ideal for asking questions about the topics presented in either lecture or lab. On Thursday and Friday, most time slots have several parallel sessions on special topics.

\section{Illustrative Example: SEM imaging in "high-current mode"}

The topic of "high-current mode" SEM microscopy may be used as an example of teaching at three different levels (Figure 3 ). The Sunday beginner's course describes the function of important control knobs on the instrument and how to take an image, without paying much attention to the amount of current in the electron beam. On Monday morning, four modes of SEM microscopy are described in lecture: resolution mode, high-current mode, depthof-field mode, and low-voltage mode. As shown in Figure 3, the more current in the beam, the greater the contrast in the image. This increase in beam current usually comes at the expense of maintaining a small beam size (except in field-emission systems), but this usually is not noticeable at magnifications less than $1000 \times$. To illustrate this point, a live demonstration of this effect, in comparison with other modes, is performed in the lecture hall via over-the-web remote control of an SEM in another building. That afternoon this same topic is covered in a laboratory where everyone can see how to set up all four SEM imaging modes for themselves. Each laboratory exercise can be accomplished on any

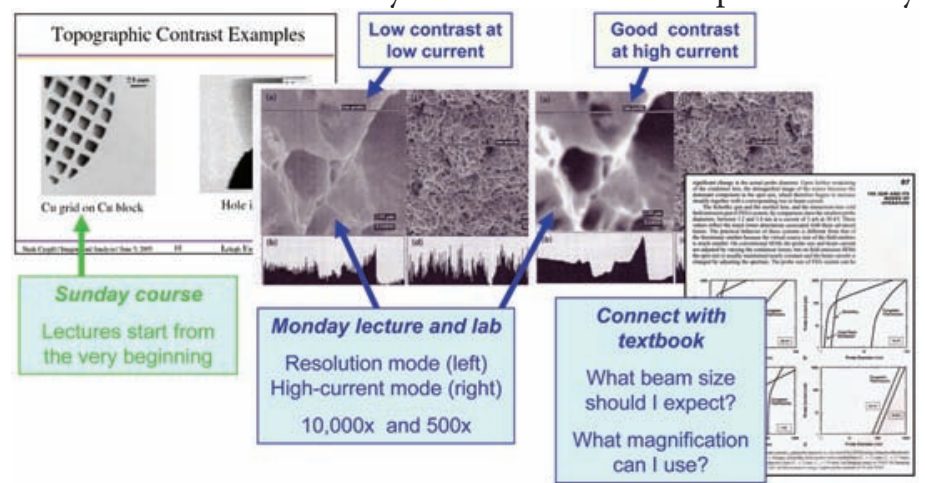

Figure 3. High-current mode. The topic of contrast in SEM imaging is introduced in the basic course on Sunday and is reiterated in greater detail on Monday, Monday's lab, and Tuesday. All topics are treated in even greater detail in the textbook.
SEM so participants are encouraged to repeat the labs on their home SEM. After the lab, participants can read about this topic in the lab workbook and the course textbook.

\section{Example: X-ray microanalysis}

The Lehigh SEM course treats X-ray microanalysis as the natural complement to SEM imaging, thus part of Tuesday and all of Wednesday are devoted to this topic. Once again, there are three levels of teaching (Figure 4). After the origins of X-ray spectra are discussed, there are several sessions to describing the information obtained from spectra and maps. The topic of element identification (qualitative analysis) is deemed particularly important since there are several pitfalls to avoid in collecting and analyzing the data (center and right side of Figure 4). It is important for the operator to understand the practical aspects of the X-ray spectrum in order to avoid misidentification of elements, even when an "automatic ID" function is employed. One of the trends in X-ray analysis is to collect data in image form, as individual X-ray maps or spectrum images. In a spectrum image, the EDS system stores an entire spectrum at each image pixel, and after acquisition, X-ray maps of individual elements may be constructed. Thus, in order to reveal the most information, the proper setup for X-ray mapping becomes important. Often lower accelerating voltages help to improve spatial resolution and visibility of details in certain elemental X-ray maps (Figure 5). If the $\mathrm{kV}$ is set too low, however, some $\mathrm{X}$-rays may not be generated with adequate intensity. One recent advance in X-ray detector technology, the silicon drift detector (SDD), allows collection of detailed X-ray maps within minutes rather than hours. The SDD is likely to become the standard type of EDS detector, further increasing interest in the topic of X-ray mapping.

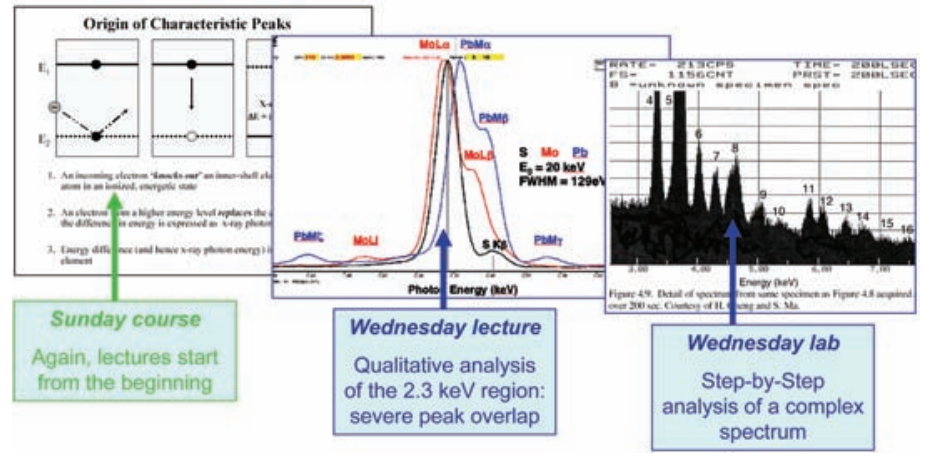

Figure 4. X-ray microanalysis is introduced in the Sunday course but is discussed in greater detail in the lectures and labs of the main SEM course. Techniques for manually identifying the peaks in the X-ray spectrum are discussed as a supplement to the automatic peak identification software embedded in all EDS systems.

\section{Special interest sessions on Thursday and Friday}

On Thursday and Friday, the participants may tailor the course to their interests by selecting optional lectures and labs from over 30 topics. The choices can be bewildering so we have organized these sessions into three tracks: X-ray analysis, imaging, and applications. Some topics are of general interest, such as specimen coating and SEM maintenance, and are recommended in all the tracks. Other topics such as electron backscatter diffraction (EBSD)are complementary to both X-ray analysis and imaging and thus are included in both of the tracks. Under the applications track there are sessions on polymer analysis, forensic 


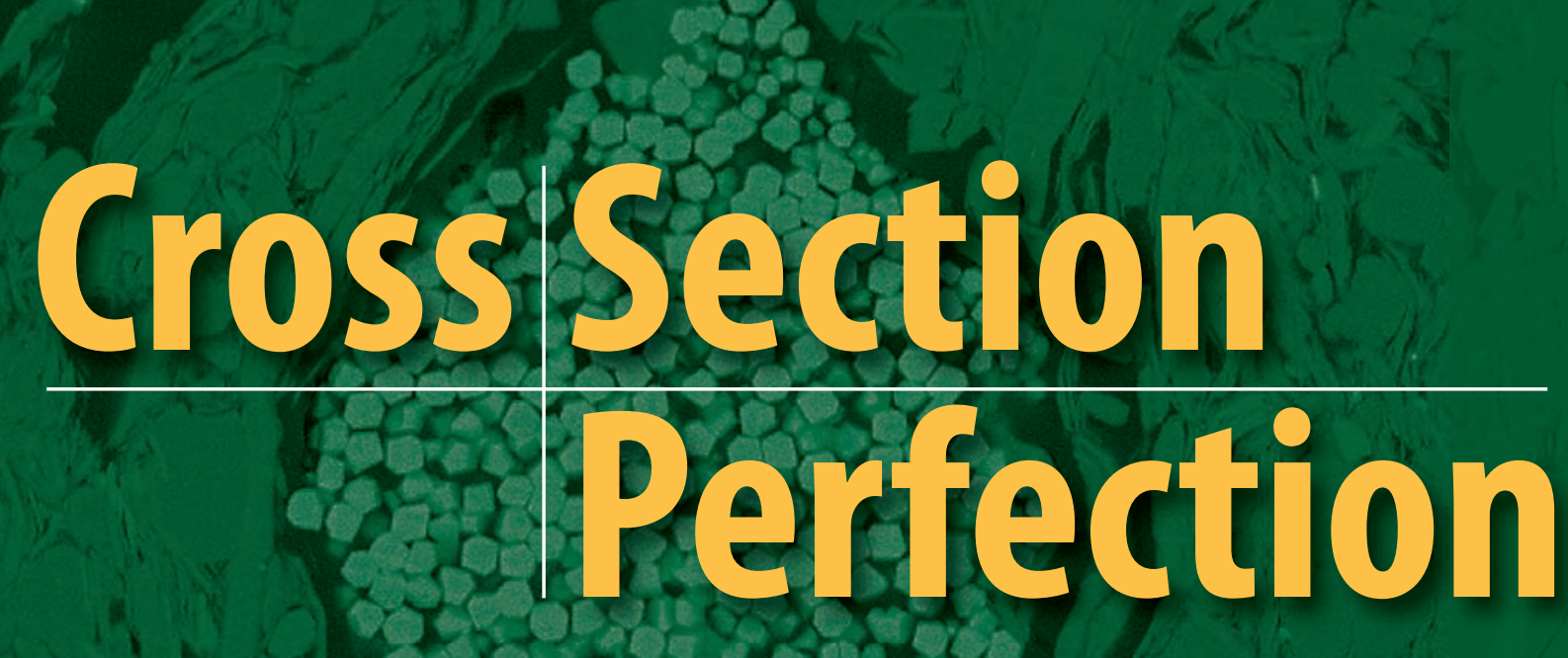

Prepare to be amazed.

.
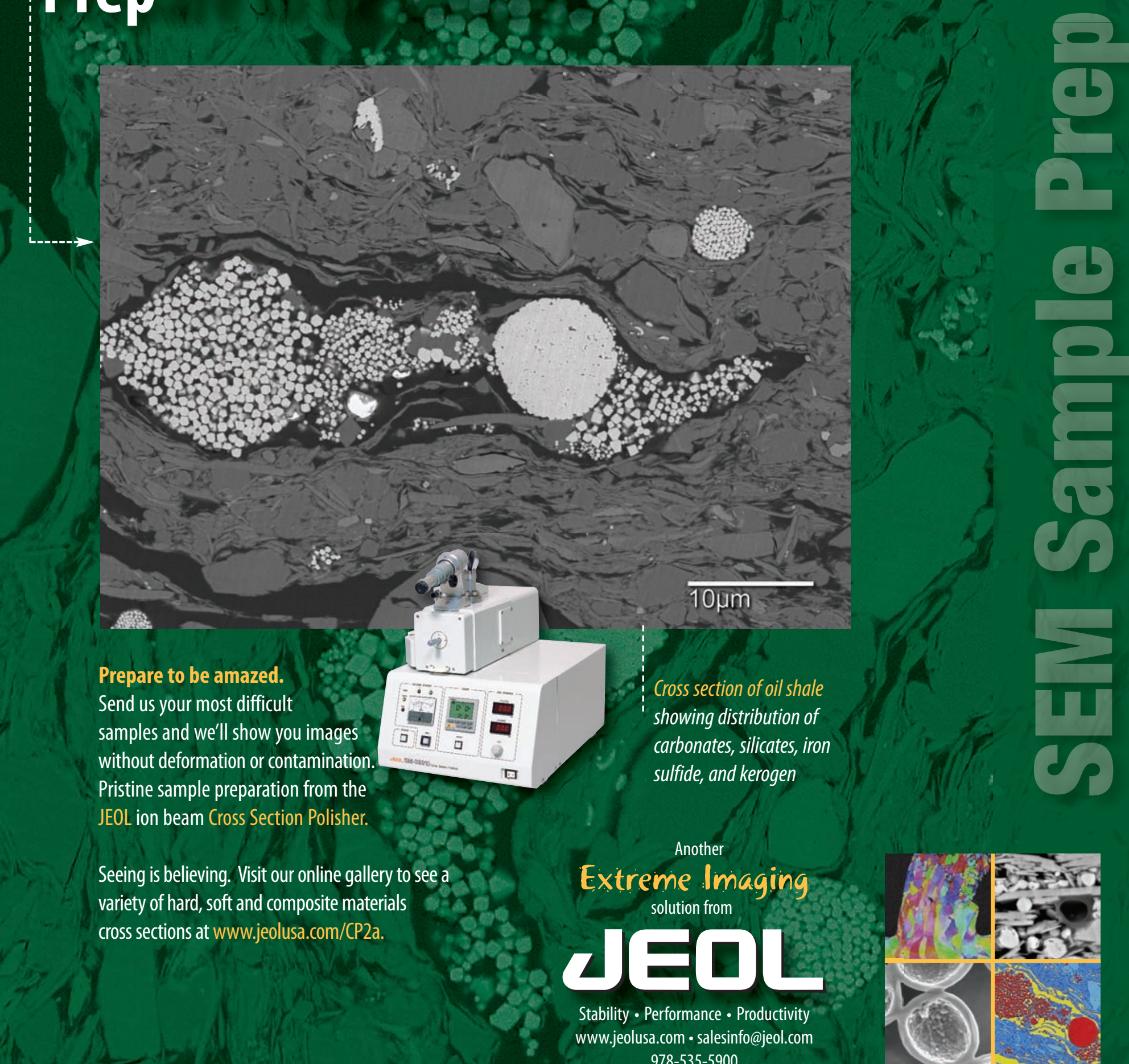


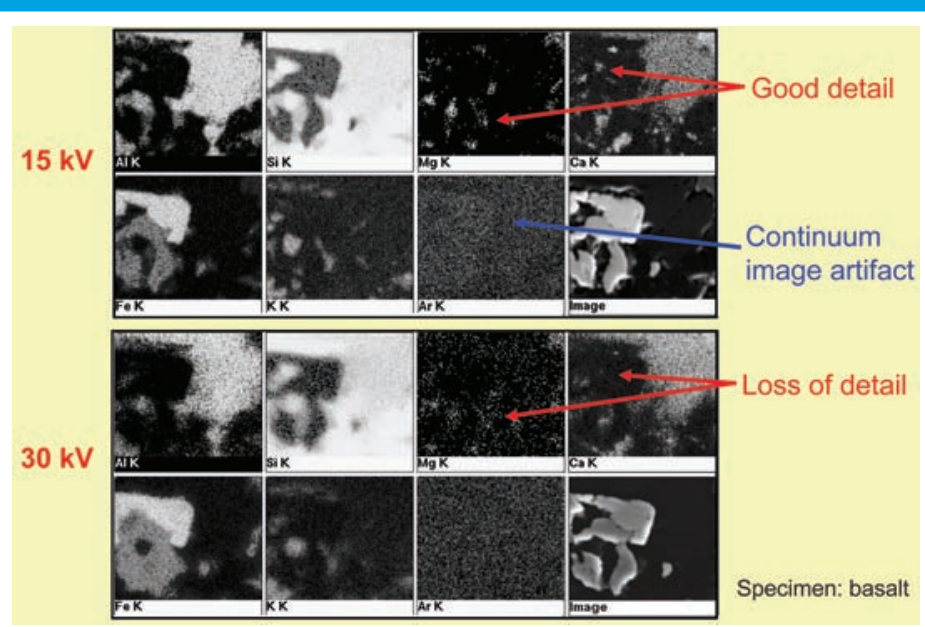

Figure 5. Practical aspects of X-ray mapping. Lower accelerating voltages cause $X$-rays of interest to be generated nearer the specimen surface yielding sharper detail for certain elements (see $\mathrm{Mg}$ and Ca images). The background image (represented by Ar K in this case) at $15 \mathrm{kV}$ shows a slight continuum image artifact at the regions rich in iron.

analysis, electronic materials, fracture analysis, and digital image analysis. During these two days, there also are open sessions on the SEMs where participants can examine their own specimens.

\section{Total immersion}

The scheduling of activities over the week is very tight. Essentially, this is a 14-week undergraduate SEM course compressed into 5 days. There is something to do from 8:30 a.m. to 10:30 p.m., though after 9 p.m. the activities are more social. With a schedule like that, it is no wonder that lecturers insert humor and "down home stories" to keep everyone awake. Participants are immersed in "SEM stuff" all day, even asking questions of lecturers at breaks and during meals. This total immersion environment appears to be effective judging from the positive participant reviews of the course. Another indicator of success is that each year about $60 \%$ of attendees are referred by people who had taken the course previously.

\section{Advanced courses}

After surviving the rigors of the flagship SEM course, participants often return another year for advanced courses held in the week following the main course. These courses include focused ion beam (FIB) technology, problem solving with SEM, quantitative microprobe analysis, scanning probe microscopy, and analytical transmission electron microscopy (AEM). These specialized courses build upon the foundation of the first-week SEM course. Additional expert lecturers are brought in for each of these advanced courses to help participants learn about the latest developments in these areas. As an example, the FIB course provides separate lectures on the many ways these instruments can be used, from making thin specimens for TEM analysis to fabricating new electronic devices to creating tomographic X-ray maps (see Figure 6).

\section{Equipment manufacturers}

SEM short courses cannot operate without the goodwill and generous technical support of many equipment manufacturers. It is essential to have skilled vendor representatives who can make their instruments work well at the pace of the laboratory exercises. Right from the first year of the Lehigh SEM course,
Joe Goldstein depended on SEMs and X-ray systems brought in just for the one-week course. In recent years, four outside SEMs from manufacturers are needed to supplement Lehigh's own microscopes. Everyone who has attended the Lehigh SEM course realizes the enormous contribution that these companies make to this educational forum.

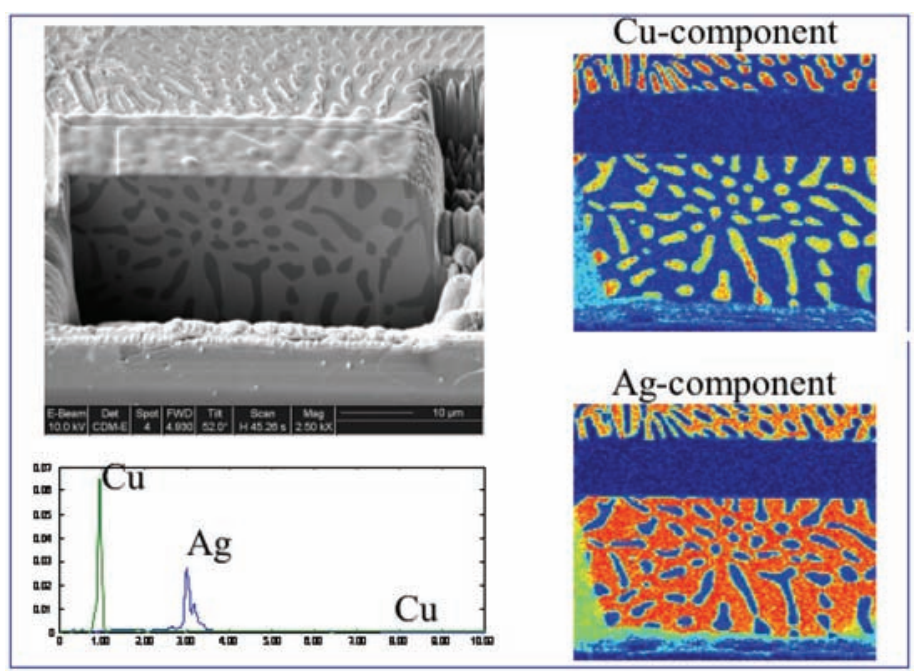

Figure 6. Advanced short course on focused ion beam (FIB) technology. Image (upper left) shows the "polished surface" produced by the FIB of a $\mathrm{Cu}$-Ag eutectic. X-ray spectrum (lower left) from the exposed specimen surface. Element X-ray maps for $\mathrm{Cu}$ and $\mathrm{Ag}$ (right) re-constructed from a spectrum image collected from the exposed specimen surface. A tomogram can be constructed by collecting a set of X-ray maps as the ion beam cuts through the specimen. (Courtesy of Joe Michael)

\section{Organization}

The organization of short courses such as the Lehigh SEM course constitutes a year-round effort. Logistics for lecture schedules, lecturers, and equipment have been handled by me and my Lehigh colleagues: Alwyn Eades, Chris Kiely, and Dave Williams (now President of the University of Alabama at Huntsville). However, every aspect of the course from meals to wireless service needs to be carefully planned and executed. This cannot be done without staff members who take a personal interest in the success of these courses. The Lehigh Microscopy School benefits greatly from the dedication and efforts of Sharon Coe, Dave Ackland, and Bill Mushock. Evaluations by the participants are critical to the success of future short courses. Each year the organizers analyze attendee evaluations to determine what works and what does not.

\section{Conclusions}

The Lehigh SEM course has been in existence for 38 years. The presentation of this course is an example of how SEM techniques can be taught to participants of varying backgrounds. The goal for all participants is to understand how to successfully acquire and interpret images and data from the SEM and its analytical attachments. Having some fun along the way is not bad either.

\section{References}

[1] Lehigh Microscopy School website: http://www.lehigh.edu/microscopy.

[2] J. I. Goldstein and H. Yakowitz (eds.), Practical Scanning Electron Microscopy: Electron and Ion Microprobe Analysis, Plenum, New York, 1975.

[3] J. I. Goldstein et al., Scanning Electron Microscopy and X-ray Microanalysis, Springer, New York, 2003. 


\section{May 31- June 12, 2009}

\section{LEHIGH MICROSCOPY}

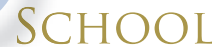

Lehigh University, Bethlehem, PA, USA

MAIN COURSES

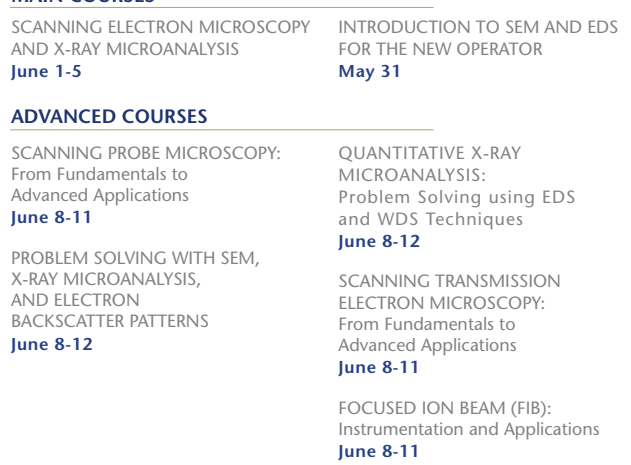

For more information, contact:

Sharon Coe I 610.758.5133 | sharon.coe@lehigh.edu
CALL FOR PAPERS

\section{DEADLINE}

is February 15, 2009:

Submit online via

http://MM2009.microscopy.org

Check out the 2009 Call for Papers online at http://MM2009.microscopy.org or in your November/December 2008 issue of Microscopy Today:

- Symposia, Tutorials, Short Courses, Workshops

- Topic List

- Submission Requirements

- Awards \& Criteria

- Posters

Submit your paper for inclusion with Biological, Instrumentation \& Techniques, or Physical Sciences symposia, including platform and poster sessions.

\section{Evactron \\ (B) \\ De-Contaminators}

Setting the Standard for RF Plasma Ashing and Removal of Carbon inside your SEM

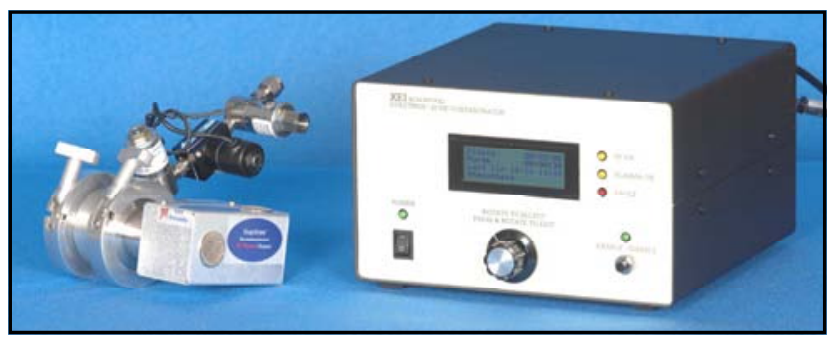

EASY TO USE - Preprogrammed conditions, starts with chamber re-evacuation.

\begin{tabular}{|c|}
\hline 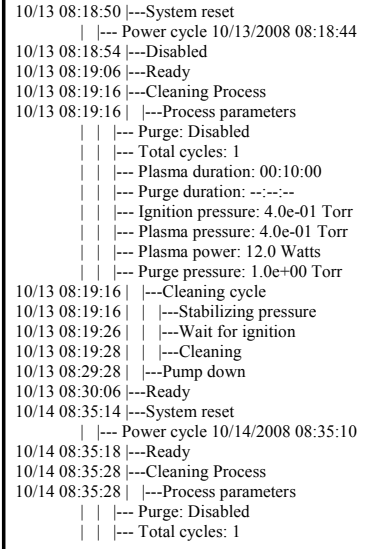 \\
\hline
\end{tabular}

\section{EASY TO MONITOR USAGE -}

Serial interface to Computer makes available an event log to correlate clean images with usage.

\section{EXCELLENT IMAGES -}

Improves

Resolution and Contrast on existing tools.

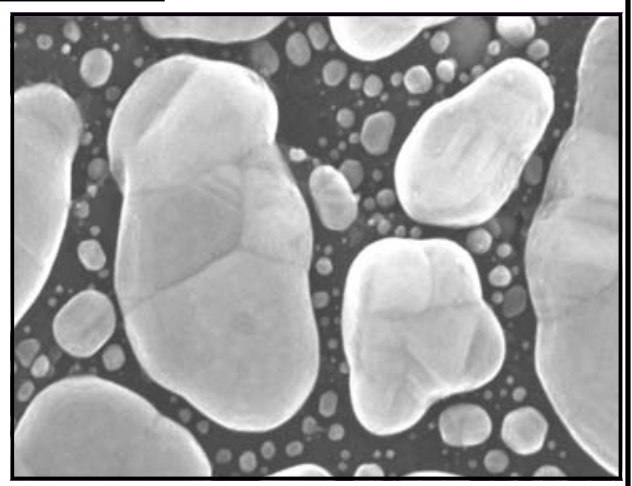

XEI SCIENTIFIC, INC. 1755 East Bayshore Rd, Suite 17 Redwood City, CA 94063 (650) 369-0133, FAX (650) 363-1659 email:sales@Evactron.com www.EVACTRON.COM 